\title{
Personas jurídicas y el órgano de control fiscalizador de las asociaciones
}

\section{Juridical persons and auditor oversight body of the associations}

Jessica Pilar Hermoza Calero* http://dx.doi.org/10.21503/lex.v11i12.25

* Doctora en Derecho de la Universidad Inca Garcilaso de la Vega, Maestra en Derecho Civil de la Universidad Inca Garcilaso de la Vega, con estudios concluidos en Maestría en Investigación y Docencia Universitaria, Conciliadora extrajudicial en materia de Derecho Civil, profesora de la Facultad de Derecho y Ciencia Política de la Universidad Alas Peruanas. 



\section{RESUMEN}

Las asociaciones se constituyen mediante un acuerdo de dos o más personas físicas o jurídicas legalmente constituidas, que se comprometen a poner en común conocimientos, medios y actividades para conseguir unas finalidades lícitas, comunes, de interés general o particular, y se dotan de los estatutos que rigen el funcionamiento de la asociación.

El artículo 80 del Código Civil lo define como una organización estable de personas naturales o jurídicas, o de ambas, que a través de una actividad común persigue un fin no lucrativo.

Se trata de una persona jurídica sumamente viva, activa, y por ello existe una enorme variedad de estas. Actualmente, el ámbito de las asociaciones se ha extendido a otros campos como recreacionales o sociales; es así que hoy en día son usadas para centros de investigación, asociaciones civiles como las ONG, etc.

La asociación como, ya se dijo, persigue fines no lucrativos, y estos se reflejan a través de dos hechos. El primero es que ninguna asociación ni la fundación o el comité distribuye las posibles utilidades que obtenga en su actividad, entre sus miembros. Si existieran excedentes, ellos deben aplicarse en el siguiente ejercicio económico a los objetivos de la institución. En segundo lugar, en el caso de disolución de una asociación, el patrimonio neto resultante de la liquidación tampoco se restituye a los asociados, sino que es destinado a propósitos análogos.

Los aportes de los asociados, por tanto, no se convierten en un crédito para ellos ni en un débito para la asociación, mucho menos para exigir el pago de utilidades. Esto marca una importante diferencia con las sociedades mercantiles, que además se refleja en el balance y la contabilidad de estas últimas.

Los fines no lucrativos son de lo más variado: educativo, cultural, deportivo, religioso, artístico, científico, recreativos, etc. y son estos los que deben ser satisfechos por medio de la asociación.

El órgano de control de las asociaciones es, en efecto, la asamblea, que controla la gestión de sus administradores reunidos en el denominado Consejo directivo, y controla a los propios asociados (sin perjuicio de las atribuciones a este respecto delegadas al Consejo).

Dada la gravitación que tiene este órgano en las funciones controladoras que ejerce, el legislador no considera conveniente la creación de un organismo estatal administrativo que se ocupe de su supervigilancia, como ocurre, en cambio, con las fundaciones. Ello, sin embargo, no elimina la posible injerencia del Estado cuando los fines o las actividades de la asociación son contrarios al 
orden público o a las buenas costumbres, en cuyo caso el Ministerio Público puede solicitar su disolución (art. 96 del Código Civil Peruano).

Palabras clave: asociaciones, Código Civil, persona jurídica.

\section{ABSTRACT}

The associations are established through an agreement of two or more natural or legal persons legally constituted, who commit to share knowledge, resources and activities to achieve a lawful purpose, common, general or special interest, and provided with the statutes governing the functioning of the association.

The article 80 of the Civil Code defines it as a stable organization of individuals and juridical persons, or both, who through a common activity pursues a non-profit purposes.

This is a legal person very lively, active, and therefore there is a huge variety of these. Currently, the association scope has spread to other areas such as recreational or social; so that today, are used for research centers, civil associations as NGOs, etc.

The association as mentioned above has non-profit purposes and these are reflected by two facts. The first one is that any association or foundation or committee distributes the possible profits obtained in its activity among its members. If there are surpluses, they must be applied in the following financial year to the objectives of the institution. Secondly, in the case of dissolution of a partnership, net assets resulting from liquidation either is returned to members, but is intended for similar purposes.

The partners' contributions, therefore, do not become a credit to them or a debit for the association, much less to demand the utility payment. This marks an important difference with commercial companies, which is also reflected in the balance sheet and the accounting of the latter.

The non-profit purposes are quiet varied: educational, cultural, sporting, religious, artistic, scientific, recreational, etc., and these are which must be satisfied by association.

The association control body is, indeed, the meeting that controls the management of its administrators gathered in the Board of Directors, and controls themselves (without prejudice to the responsibilities to this delegated to the Board).

Given the importance that this body has in the control functions that practices, the legislator does not consider convenient the creation of a state administrative agency that deals with its supervision, as instead, with the foundations. It, however, does not eliminate the possible interference of State when purposes or activities of association are opposite to the public order or morality, in which case the Attorney General's Office can ask for its dissolution (Article 96 of Peruvian Civil Code).

Key words: associations, Civil Code, juridical person. 


\section{INTRODUCCIÓN}

Este es un importante tema para la mejora en nuestro país, porque aporta soluciones integrales al tema de las asociaciones, que se crean con una finalidad general y particular; sus miembros forman una constitución corporativa y en su constitución tiene que haber un acta constitutiva que se complemente con los estatutos y que debe estar inscrita en los registros públicos.

El presente ensayo tiene por objetivo dar a conocer el verdadero significado de las personas jurídicas, incluyendo a las asociaciones, y que efectivamente no existe un organismo fiscalizador de control que se aboque a poder orientar la buena marcha de las asociaciones y organizaciones no gubernamentales, en vista de que sí existe una entidad fiscalizadora para las fundaciones y comités.

Las asociaciones están conformadas por un grupo de dos o más personas que persiguen una finalidad no lucrativa. Busca, más bien, un beneficio dirigido a la reinversión de la propia asociación a la que pertenecen. Si es así, se denomina asociación con fines particulares, en cuyo caso las ganancias que obtengan serán para la propia asociación. En caso de que las ganancias estén dirigidas a ayudar a terceras personas, estamos frente a las asociaciones con fines generales.

Una vez que se han formalizado legalmente las asociaciones, estas pueden ejercer las actividades que ordenan sus estatutos, como es el cumplimiento de las asambleas para tomar sus acuerdos en bien de la asociación, y también para el balance de sus economías, para lo cual contará con los miembros que integran la parte directiva de la asociación y que fueron elegidos legalmente por una asamblea.

Por otro lado, observamos que cuando existe alguna contradicción en los estatutos de las asociaciones, los interesados pueden presentar un reclamo ante INDECOPI o ASPA para que puedan resolver sus problemas, pero no hay un ente fiscalizador para la supervisión de las asociaciones, teniendo en cuenta que una vez formalizadas e inscritas debidamente ante los 
Registros Públicos, deberían permanentemente ser orientadas para que cumpla la finalidad perseguida o culmine exitosamente.

En nuestro país existen 101 mil 180 organizaciones sociales de base, de las cuales 67 mil 389 son comités de vaso de leche, 17 mil 842 comedores populares y 15 mil 949 clubes de madres; y en conjunto representan el $52,2 \%$ del total de instituciones sin fines de lucro. Además, el 26,2 \% son asociaciones de padres de familia (APAFA), 4,8 \% son organizaciones educativas y el 13,8\% comprende al resto de instituciones sin fines de lucro.

\section{DEFINICIONES}

La persona jurídica es el ente apto para ser titular de derechos o deberes, y tiene la capacidad que la ley le reconoce como tal, es decir, se le reconoce, como a una persona, entidad, asociación o empresa, capacidad suficiente para contraer obligaciones y realizar actividades que generan plena responsabilidad jurídica, frente a sí mismos y frente a terceros.

Según Enneccerus, la asociación es "la unión estable de una pluralidad de personas, independientemente del cambio de miembros, que tiene una constitución corporativa y un nombre colectivo, correspondiendo la administración de los asuntos de la asociación a los miembros". ${ }^{1}$

Podríamos decir que la asociación es una organización interna que tiene una estabilidad corporativa, que los asociados se reúnen por voluntad y libertad propia, que es autónoma porque la voluntad emana de sus propios miembros, que no tiene ánimo de lucro, que su forma de constitución tiene que establecer estatutos y que debe estar inscrita debidamente en los Registros Públicos.

Se diferencia de la fundación en que en la asociación prevalece el elemento personal, en tanto que en las fundaciones se privilegia el elemento patrimonial. Las asociaciones son autónomas, porque la voluntad emana de sus miembros; las fundaciones son heterónomas, porque la voluntad emana de su fundador.

Las asociaciones pueden ser permanentes o transitorias, simples o complejas, extensas o limitadas. Surge, por un acto constitutivo en el que un grupo de personas de común acuerdo resuelve asociarse para la obtención de un fin de naturaleza ideal o económica, determinando los derechos y obligaciones de los socios. A este acto constitutivo lo acompaña y complementa el estatuto, que dicta normas sobre la organización, es decir, estatuye cláusulas contractuales.

Una asociación tiene que regirse por el principio de la mayoría, es decir, todas las decisiones que se tomen deben ser consecuencia de la voluntad de la mayoría de los socios, expresada en una asamblea social. Este principio rige para todas las deliberaciones de la asamblea.

1 Enneccerus. Libro de personas juridicas. Primera parte General. Vol I. 
Se pueden disolver las asociaciones por causas previstas en los estatutos o por deliberación de la asamblea o por supresión decretada por la autoridad. ${ }^{2}$

El organismo que fiscaliza la asociación es INDECOPI, que se encarga de administrar los actos constitutivos o modificatorios correspondientes a las sociedades de gestión colectiva y derechos conexos.

La asociación es una organización estable, conformada por personas naturales o jurídicas, o ambas, que a través de un trabajo común persiguen un determinado objetivo que es de carácter no lucrativo.

Según el artículo 2, inciso 13, de la Constitución Política del Perú, "toda persona tiene derecho a asociarse y a constituir fundaciones y diversas formas de organización jurídica sin fines de lucro, sin autorización previa y con arreglo a ley...”, es decir, este artículo defiende la libertad que tienen las personas de agruparse con un objetivo común, y estas agrupaciones pueden ser inscritas y no inscritas, pero siempre van a estar reguladas por la ley, ya que el Estado funciona como un ente normativo y regulador de la sociedad.

Según Mario Seoane, "la asociación tiene las notas esenciales de la mayoría de personas jurídicas, como son la pluralidad de miembros, el fin común permanente lícito y posible, la organización y el cumplimiento de formalidades exigidas por la ley"; esto significa que la asociación para constituirse debe cumplir con algunos requisitos, toda vez que una asociación no puede ser formada por un solo miembro, sino que es de dos a más, que realizan actividades con miras de un objetivo que puede ser económico, cultural, etc.; y además, este objetivo debe estar dentro de los parámetros de la ley y debe ser realizable, no algo utópico; asimismo, la asociación tiene una organización interna y se debe desenvolver dentro de los márgenes de la ley.

Según Mario Seoane, los pasos para constituir la asociación son los siguientes:

1. El acto constitutivo es el primer acuerdo, además de ser un negocio jurídico que requiere para su validez de los requisitos establecidos en el artículo $140^{\circ}$ del Código Civil, que son los siguientes: el objeto debe ser física y jurídicamente posible, el fin lícito, y la observancia de la forma prescrita por la ley bajo sanción de nulidad.

2. El estatuto viene a ser la norma interna que regula a la asociación.

3. En el contenido del estatuto encontramos normas referentes a la duración, al domicilio, a los fines, los miembros, etc.

4. El reconocimiento de la asociación se rige a partir de su inscripción en Registros Públicos.

2 Mario Seoane . Personas jurídicas. Perú: Editorial Grijley, 2005, pp. 32-33. 
5. Todas las asociaciones deben contar con el libro de registro de la asociación, libro de actas de asambleas de los asociados y del consejo directivo.

Cabe destacar que no hay un ente regulador propio de las asociaciones. Las asociaciones se regulan por sus estatutos, la participación de cada miembro y por lo que ordena el Código Civil. Cuando hay alguna irregularidad, se recurre a INDECOPI para presentar el reclamo respectivo como lo haría cualquier otra organización.

\section{Persona jurídica}

\section{Definición}

Según el jurista Mario Seoane, el hombre es el creador del Derecho, y este es un medio que le sirve para relacionarse "ordenadamente con los demás seres humanos", ejerciendo deberes y facultades; el hombre es un ser individual con trascendencia social, que busca la unión y colaboración con sus semejantes, ofrecido su esfuerzo personal y su patrimonio para tratar de alcanzar una finalidad; por ello puede desenvolverse tanto a nivel individual como colectivo.

Como ya hemos dicho, el espíritu asociativo del ser humano se encuentra presente en todos los tiempos, de próximos a remotos, porque ha sido una condición de la existencia y el desarrollo de las civilizaciones.

Las personas pueden crear organizaciones con finalidades culturales, altruistas, históricas o económicas; en todos los casos, la regla general es que un conjunto de personas se une para la realización de fines valiosos y adopta la forma de persona jurídica.

Ahora bien, ¿la colectividad jurídica requiere en todos los casos de la pluralidad de personas? La experiencia legislativa nos dice que no. Dentro de la personalidad jurídica hay modalidades y existen algunas que pueden ser constituidas por una sola persona. Un ejemplo de ello es la Empresa Individual de Responsabilidad Limitada o la Sociedad Unipersonal.

Del mismo modo, como sostiene Angarita Gómez en su libro Lecciones de Derecho Civil, la simple asociación de hombres o la decisión unipersonal para un fin determinado es insuficiente por sí misma para alcanzar la personalidad; ello requiere el "reconocimiento" del ordenamiento jurídico, de tal manera que los efectos de los actos se concentren en un sujeto de derecho, que es una individualidad distinta e independiente del miembro o miembros que la componen.

El reconocimiento, dice Ferrara, determina la personalidad (capacidad) y, por ende, la forma unitaria en la que se imprime el sello jurídico de las organizaciones sociales. Entonces, la expresión personas jurídicas alude a una entidad unitaria, cumpliendo con las formalidades 
previas en la ley para realizar determinadas actividades dirigidas al cumplimiento de finalidades reconocidas por el ordenamiento jurídico.

Esta entidad con caracteres unitarios, desde el punto de vista objetivo, al adquirir la personalidad, se incorpora a una categoría con efectos determinados por el ordenamiento jurídico. Como consecuencia de ello, vamos a presenciar una forma de imputación normativa, es decir, los actos de la entidad son finalmente realizados por personas individuales — sus representantes - , pero esos actos y sus mismos efectos son imputados a la propia entidad.

En mi opinión, la idea y expresión de personas jurídicas se dirige a una o varias personas que se organizan en forma voluntaria, cumpliendo con formalidades descritas en la ley, para realizar una serie de actos dirigidos al logro de fines y objetivos en común y reconocidos por el ordenamiento jurídico.

\section{Asociación}

\section{Definición}

La asociación es una organización estable de personas naturales o jurídicas o ambas que, a través de una actividad común, persiguen un fin no lucrativo. La actividad común vincula e identifica a sus miembros con las expectativas y los resultados de la organización, la cual asume el costo y riesgo de su propia actividad.

En tanto organización, la asociación se concibe como medio necesario para que la autonomía de las personas se expanda a formas de convivencia inspiradas en valores solidarios y fructíferos, así como medio de expresión del derecho constitucional de asociación de la organización, la cual asume el costo y riesgo de su propia actividad.

Asimismo se concibe como medio necesario para que la autonomía de las personas se expanda a formas de convivencia inspiradas en valores solidarios y fructíferos, así como medio de expresión del derecho constitucional de asociación de la persona, recogido por el artículo $2^{\circ}$, inciso 13 , de la Carta Política, que consagra la libertad de la persona de asociarse, constituir fundaciones y diversas formas de organizaciones jurídicas sin fines de lucro, "sin autorización previa y con arreglo a ley", con la prerrogativa de que estas organizaciones no pueden ser disueltas por resolución administrativa.

\section{Caracteres}

La asociación tiene las notas esenciales de la mayoría de personas jurídicas, como son la pluralidad de miembros, el fin común permanente lícito y posible, la organización y el cumplimiento de formalidades exigidas por ley: ${ }^{3}$

3 Juan Espinoza Espinoza. Derecho de las Personas. Cuarta edición. Gaceta Jurídica, 2004. 
1. Constitución de la asociación

1.1 El acta constitutiva
a. Agentes capaces
b. Objeto física y jurídicamente posible
c. Fin lícito
d. Observancia de la forma prescrita por la ley bajo sanción de nulidad

1.2. El estatuto

\subsection{Contenido del estatuto}

\subsection{Reconocimiento}

1.5. Libros de la asociación

\section{DEBERES Y DERECHOS DE LOS ASOCIADOS}

Los asociados pueden ejercitar sus derechos a título individual y colectivo de acuerdo con el procedimiento establecido en el estatuto o la ley.

El asociado tiene los derechos inherentes a su calidad de tal, de acuerdo a lo que determinan los estatutos. Hablando en términos generales, podrá utilizar los beneficios y servicios que brinda la asociación para sus miembros, como son utilización del local para los fines sociales pertinentes, concurrir a las sesiones de las juntas generales, opinar y votar, y ser elegido para cargos directivos. ${ }^{4}$

Ahora bien, podemos notar que la asociación es conjunto de personas jurídicas con determinados fines no lucrativos. Estos fines persiguen el bienestar colectivo prestando bienes y servicios. También se resalta que cualquier persona sin discriminación alguna puede formar una asociación siempre y cuando siga la norma interna que regula la estructura y el funcionamiento de la asociación, la misma que debe estar registrada en escritura pública, salvo disposiciones distintas en la ley. Es importante resaltar que los asociados disfrutan de los beneficios que su esfuerzo en común les permita lograr. Asimismo, esta finalidad común puede ser de interés particular de los asociados. Para construir una asociación, debe existir por lo menos certeza de su obtención y del aporte de sus miembros. En cuanto al régimen, se determina por el estatuto aprobado por sus miembros. Las asociaciones no cuentan con un órgano público que las supervive permanentemente.

4 José León Barandiarán. Tratado de Derecho Civil. Lima: UNMSM, 1963, p. 66. 


\section{INDECOPI}

\section{Funciones}

El INDECOPI tiene como función supervisar la competencia y asegurar el desarrollo de una política de libre mercado. Entre una de sus obligaciones está el de contribuir a mantener las reglas estables y hacer que los consumidores y los empresarios sean conscientes de su relación de consumo.

Es el órgano que vela para que se respeten las disposiciones contenidas en la Ley de Protección al Consumidor.

\section{Facultades}

- Impone sanciones diversas que van desde una amonestación hasta multas de 100 UIT ( US\$94 000)

- Decomisa o destruye mercadería.

- Clausura temporal de establecimientos.

- Publicación de avisos rectificatorios.

- Repara o repone productos.

- Devuelve la suma pagada por el consumidor.

\section{Motivos para regular}

- Garantizar el acceso al servicio (universalidad), como la fijación de tarifas básicas y de su acceso por parte de los sectores con menores recursos.

- Proteger los intereses de los usuarios, respondiendo a sus consultas y reclamos.

- Supervisar las operaciones de empresas privatizadas o en monopolios públicos. Por ejemplo, mediante la regulación de precios respecto a la calidad deseada del servicio.

- Estimular la innovación. El regulador debe crear el ambiente para el crecimiento y desarrollo del servicio.

- Modificar la estructura de la industria. Por ejemplo, facilitando la entrada de nuevas empresas para fortalecer el nivel de competencia.

- Garantizar reglas equitativas a todos los competidores, es decir, entre las nuevas empresas y las ya existentes. 


\section{Lo que se debe regular}

- Los estándares técnicos y operativos de los operadores y de sus operaciones.

- Los estándares de calidad del producto o servicio que ofrecen.

- Los precios.

\section{Autonomía de la función reguladora}

Alude a la manera en que la institucionalidad reguladora se inserta en la maquinaria estatal. Esto va a depender del balance entre las fuerzas de los regulados (administrados), de las autoridades políticas y de los usuarios, así como de la discrecionalidad respecto de las normas establecidas y de la legitimidad que ampara sus decisiones.

\section{Relación entre el financiamiento y la autonomía en la regulación}

Más allá de su inserción formal en el aparato público, buena parte de la independencia efectiva del regulador está asociada a su financiamiento. Ambos aspectos están, por otra parte, bastante vinculados. Normalmente, cuanto más autónomo del gobierno es un organismo regulador, también lo es su fuente de financiamiento. En efecto, un organismo regulador ubicado dentro de un Ministerio se financia por lo general con fondos presupuestarios. Ello establece, con mucha frecuencia, límites al volumen y la utilización de los recursos, redundando en remuneraciones poco competitivas, equipamiento deficiente y mayores posibilidades de captura del regulador. El menor costo puede traducirse, así, en un sacrificio considerable de la efectividad. El extremo opuesto, de absoluta autonomía del regulador, implica la independencia en materia financiera a través de una contribución mandataria de los mismos administrados. En este caso, la calidad y efectividad tienden a verse incrementadas, aunque la posibilidad de captura no desaparece por la influencia que pueden causar justamente los administrados con mayor contribución.

\section{Los organismos reguladores en el Perú}

La Ley No 27332 publicada el 29 de julio del 2000, Ley Marco de los Organismos Reguladores de la Inversión Privada en los Servicios Públicos, establece la naturaleza de los organismos reguladores, su ámbito de aplicación y sus facultades, así como el financiamiento de los mismos. Se asignan a los organismos reguladores las funciones de supervisión, regulación, fiscalización y sanción, normativa, solución de controversias y reclamos. ${ }^{5}$ 


\section{LA PERSONA JURÍDICA EN EL CÓDIGO CIVIL PERUANO}

La persona jurídica en la actualidad ha adquirido una gran relevancia para el Derecho moderno. Siguiendo esta tendencia, los diversos Estados se han preocupado por incluirla dentro de su ordenamiento, y en muchos casos definiéndola, clasificándola o regulándola. Ahora bien, dentro de nuestro ordenamiento jurídico, este concepto jurídico se encuentra incluido en el Libro Primero, Derechos de las personas, sección segunda del Código Civil; estando regulada propiamente en los artículos del 76 al 79.

Echando un vistazo a nuestro Código, podemos dar cuenta de que este no define propiamente qué es una persona jurídica, a diferencia de otros códigos, sino que este comienza su regulación haciéndonos mención de la capacidad. Otro punto en mención es que en nuestro ordenamiento la persona jurídica tiene vigencia desde el momento en que se inscribe en los registros públicos. Sin embargo, es necesario realizar un pequeño análisis de los artículos que comprende la persona jurídica, a saber:

Art. 76. La existencia, capacidad, régimen, derechos, obligaciones y fines de la persona jurídica se determinan por las disposiciones del presente Código o de las leyes respectivas. ${ }^{6}$

La persona jurídica de Derecho Público interno se rige por la ley de su creación.

Este artículo, que constituye una norma de carácter general, señala y estipula las fuentes del Derecho que van a ser usadas si se produce su existencia. Trata de su existencia, capacidad, régimen, derechos, obligaciones, así como de la finalidad de las personas jurídicas del llamado Derecho Privado, en tanto organizaciones de personas que persiguen fines valiosos y que, normativamente, se constituyen como centros ideales unitarios de imputación de situaciones jurídicas.

Según esto, las personas jurídicas están regidas por el Código Civil vigentes y las leyes pertinentes al caso, claro está que siempre subordinadas al Código Civil.

A diferencia de las asociaciones, fundaciones, comités y comunidades campesinas y nativas, que también están normados por el Código Civil, existen también otras personas jurídicas que pueden ser creadas mediante leyes especiales. Estas son las cooperativas, sindicatos, comunidades laborales y otras organizaciones con un interés preponderantemente privado. Sin embargo, a pesar de que estas personas jurídicas son creadas por normas especiales, también se les aplica las disposiciones generales del Título Preliminar del Código Civil.

Art. 77. La existencia de la persona jurídica de Derecho Privado comienza el día de su inscripción en el registro respectivo, salvo disposición distinta de la ley. La eficacia de los actos celebrados en

6 INDECOPI. Decreto Ley No 25868. Noviembre de 1992. 
nombre de la persona jurídica antes de su inscripción queda subordinada a este requisito y a su ratificación dentro de los tres meses siguientes de haber sido inscrita. Si la persona jurídica no se constituye o no se ratifican los actos realizados en nombre de ella, quienes los hubieran celebrado son ilimitada y solidariamente responsables frente a terceros.

Para que el ordenamiento jurídico reconozca a la persona jurídica, esta se tiene que inscribir en los Registros Públicos, salvo disposición distinta de la ley.

Así, la persona jurídica será un sujeto de derechos y deberes distintos de los miembros que la componen desde el día de su inscripción, por lo que es recién desde ese momento que tendrá existencia en el ordenamiento jurídico. Pero es posible que antes de constituirse e inscribirse en los registros públicos, se vea en la obligación de realizar algunos actos jurídicos como puede ser el de compraventa de un bien, el de arrendar algún local, etc.

Por este motivo, nuestro actual Código en el presente artículo establece que la eficacia de dichos actos queda subordinada a la ratificación dentro de los tres meses de constituida la persona jurídica. Lo que queda subordinado a la ratificación es la eficacia del acto respecto de la persona jurídica. Si el acto no es ratificado, los efectos de dicho acto recaerán sobre la persona que lo celebro.

El artículo establece, en ese sentido, que quienes hayan celebrado el acto son ilimitada y solidariamente responsable frente a terceros si la persona jurídica no se constituye o no ratifica el acto.

Esta ratificación constituye un requisito, junto con la inscripción, para que los actos celebrados en nombre de la persona jurídica antes que se constituya sean eficaces respecto a esta.

Si la persona jurídica no se inscribe en el registro o si los actos no se ratifican dentro de los tres meses siguientes de haber sido inscrito en los registros públicos, los actos celebrados en nombre de ella no serán oponibles y serán de entera responsabilidad de quienes los hubieran celebrado. Además, la responsabilidad será solidaria entre estos. ${ }^{7}$

Según los argumentos mostrados por el autor, hay que hacer una pequeña referencia sobre la inscripción de la persona jurídica para que adquiera sus derechos, pues existen excepciones que a la vez son erróneas y en las cuales no es necesaria la inscripción para que se adquiera la personalidad jurídica.

Así, la ley $\mathrm{N}^{\circ} 27157$ establece el reglamento de la junta de propietarios, y conforme al artículo 46 de dicha ley, se establece la inscripción en el Registro de Propiedad del Inmueble

www.gerencie.com. Derecho civil. 
(Registro de Predios). Esta disposición generó que algunas personas estimen que esta simple inscripción les otorgaba personería jurídica o estatus de persona jurídica, lo que suponía que la junta de propietarios estaba sujeta a los derechos y deberes naturales de una persona jurídica, aunque fuera de manera limitada.

Sin embargo, esto se puede considerar erróneo porque en ningún momento se establecía que una junta de propietarios que se inscribía en Registros Prediales adquiría una figura de persona jurídica.

Por ello, a pesar de que la junta de propietarios no cumpla todos los requisitos de persona jurídica, nuestra legislación la considera como patrimonio autónomo, por lo que puede adquirir derechos y obligaciones, los cuales siempre deben estar vinculados con la Ley 27157.

\section{OTRAS FORMAS ASOCIATIVAS}

\section{Organizaciones no gubernamentales de desarrollo}

Son personas jurídicas no lucrativas que adicionalmente se han inscrito en un registro administrativo denominado Registro de Organizaciones no Gubernamentales de Desarrollo, Receptoras de Cooperación Técnica Internacional (ONGD-PERU), que tienen carácter constitutivo (administrativamente). ${ }^{8}$

Funcionan con la finalidad de obtener donaciones o subvenciones de Entidades e Instituciones de Cooperación Técnica Internacional (ENIEX), las cuales tienen que inscribirse también en un registro administrativo, conducido por el Ministerio de Relaciones Exteriores (artículo 70 del Reglamento).

\section{Organizaciones sociales de base}

Son organizaciones que utilizan la forma corporativa de asociación para el cumplimiento de sus fines. Han sido creadas al amparo de la Ley $\mathrm{N}^{\circ}$ 25307, cuya ordenanza 51-93-MLM y el Decreto de Alcaldía $N^{\circ} 41$ han reglamentado su situación solo en la provincia de Lima.

Estas organizaciones nacen para legitimar las organizaciones populares creadas para realizar acciones dirigidas a procurar medios de subsistencia, autogestión, defensa de intereses de carácter gremial, popular, local u otros análogos. Pueden organizarse como organizaciones sociales de base los comedores populares, clubes de madres, comités de vaso de leche, centros familiares, centros materno-infantiles, etc., que no tengan fines lucrativos o afiliación política.

8 Juan Espinoza Espinoza. Derecho de las Personas. Cuarta edición. Lima: Gaceta Jurídica, 2004. p. 804. 
El registro municipal autoriza el funcionamiento de la organización dentro de los límites de la competencia del gobierno local, lo que debe convalidarse con la inscripción registral que determina que la organización social de base es una entidad distinta de sus miembros y además con patrimonio propio.

\section{Asociaciones de padres de familia (APAFA)}

Se encuentran en los centros de educación inicial, especial, primaria, secundaria, estatal y no estatal, y están reguladas por el D. S. Nº18-88-ED. Estas asociaciones están constituidas por padres o apoderados de los alumnos matriculados en cada centro educativo, que mantienen la condición de miembros mientras el hijo se encuentre matriculado. La finalidad de esta asociación es participar en el proceso educativo de los hijos de sus miembros.

Para que pueda realizar sus funciones, debe ser promovida por la dirección del centro educativo correspondiente. El acto de reconocimiento de la asociación tiene efectos funcionales, pues no significa que la organización tenga personería jurídica, ya que para ello se requiere de la inscripción en el registro. La denominada asociación es una organización con estructura propia, y se podría considerar como organización de personas no inscritas. Se encuentra regulada por los artículos 124 y 55 del Código Civil. 


\section{CONCLUSIONES}

- Primera. La asociación tiene miembros y una administración propia. Su forma de constitución es autónoma, y tiene que haber cláusulas contractuales donde se estipulen sus derechos y obligaciones. Las decisiones deben ser tomadas por la mayoría de los socios, y pueden disolverse por algunas disposiciones en los estatutos.

- Segunda. El derecho no actúa por voluntad unilateral de una fuerza, sino que es producto de cambios sociales y de las diversas fuerzas que intervienen en las relaciones cotidianas.

- Tercera. Una persona jurídica es todo ente con capacidad para adquirir derechos y contraer obligaciones y que no sea una persona física. Así, junto a las personas físicas existen también las personas jurídicas, que son entidades a las que el Derecho atribuye y reconoce una personalidad jurídica propia y, en consecuencia, capacidad para actuar como sujetos de derecho, esto es, capacidad para adquirir y poseer bienes de toda clase, contraer obligaciones y ejercitar acciones judiciales.

- Cuarta. La personalidad jurídica es una ficción creada por el Derecho para articular otro derecho fundamental como el derecho de asociación, que debido a la evolución capitalista y a la importancia de la acumulación se hace día a día más importante para el desarrollo de la sociedad estable.

- Quinta. Frente a las dificultades para formar un capital sólido de manera individual, se crean ambientes propicios para fomentar el desarrollo industrial basado en la solidaridad colectiva.

- Sexta. La asociación es un sujeto de derechos y obligaciones que existe no como individuo sino como institución, y es creada por una o más personas físicas para cumplir un objetivo social que puede ser con o sin ánimo de lucro.

- Sétima. Ante una persona jurídica existe alternativamente un ente para cada especialidad de empresas, y es así como la asociación se mantiene.

- Octava. La Asociación Peruana de Consumidores y Usuarios (ASPEC) no sería un ente que fiscalice a las asociaciones, por cuanto se trata también de una asociación que está en defensa de los consumidores pero no propiamente de la persona jurídica, como ocurre cuando hablamos de las asociaciones. Este sí sería el caso de las fundaciones, que tienen un órgano fiscalizador, como es el consejo de supervigilancia.

- Novena. ASPA e INDECOPI son organismos defensores de todos los abusos que se cometen contra los consumidores, mas no son entidades autónomas que se dediquen solo a la fiscalización de las asociaciones. 


\section{RECOMENDACIONES}

1. Las personas que decidan formar una asociación, primero deben establecer sus estatutos y luego inscribirla debidamente en los Registros Públicos. Es bueno hacer la aclaración de que las personas no deben confundir asociación con fundación, ya que tienen significados muy diferentes y se aplican de manera distinta.

2. Las asociaciones deben mantener su autonomía exclusiva de una autoridad que las supervise. Puesto que no existe una entidad fiscalizadora propia, tiene que hacerse cargo de algunas irregularidades que puedan desarrollarse frente a una asociación como el INDECOPI, que es el órgano fiscalizador de los negocios en general.

3. Debe adicionarse un artículo que se refiera a la fusión de asociaciones, a fin de que permanezca o se recupere y que no se disuelva la persona jurídica.

4. En los estatutos de las asociaciones se debe insertar un artículo que considere un órgano superior a cargo de la fiscalización y buen funcionamiento de las asociaciones como personas jurídicas y que reciba la protección del Estado con respecto a las capacitaciones.

5. Las asociaciones deberían fusionarse cuando una de ellas decida desaparecer a causa de contar con poco capital para continuar funcionando.

\section{REFERENCIAS}

- Constitución Política del Perú de 1993

- Enneccerus. Libro de personas jurídicas. Primera parte General. Vol I.

- Espinoza Espinoza, Juan. Derecho de las Personas. Cuarta edición. Gaceta Jurídica, 2004.

- Fernandez Sessarego, Carlos. Derechos de las personas. Undécima edición. Lima: Cultural Cuzco, 2011.

- Gómez, Angarita. Lecciones de Derecho Civil. Bogotá: Temis, 1998.

- León Barandiarán, José. Tratado de Derecho Civil. Lima: UNMSM, 1963.

- Reale, M. Introducción al Derecho. Madrid: Ediciones Pirámide, 1984.

- Seoane, Mario. Personas jurídicas, Principios generales y su regulación en la legislación peruana. Lima: Editorial Jurídica Grijley, 2005. 